\title{
Mechanistic data support protecting non-smokers from the lethal effects of second-hand smoke
}

\author{
Robert Laumbach • Howard Kipen
}

Received: 20 March 2014/Accepted: 24 March 2014/Published online: 30 April 2014

(C) Swiss School of Public Health 2014

In 1998 when California became the first major jurisdiction to ban smoking in bars, Paul Blanc and colleagues took advantage of this natural (governmental) experiment to advance our understanding of the health impact of secondhand smoke (SHS) on non-smokers. Anticipating the reduction in exposure, they studied 53 bar tenders before and 2 months after the ban, demonstrating clear improvements in pulmonary function (Eisner et al. 1998). Although previous studies had demonstrated reduced symptoms following exclusion of smoking from workplaces, this was the first study to employ objective biomarkers of dysfunction. Sixteen years later, data are still being marshaled to clarify the health implications of eliminating smoking from workplaces, with an important contribution by Rajkumar et al. in this issue of the International Journal of Public Health (Rajkumar et al. 2014).

Taking advantage of the non-uniform distribution of recent smoking bans in Swiss hospitality workplaces, they measured biomarkers of cardiovascular effects, before and after the bans, in 55 non-smoking hospitality workers who worked in venues targeted for a smoking ban, compared to 23 controls who had continued exposure to SHS. A major strength of this study was the use of nicotine badges to quantify smoke exposure as cigarette-equivalents-per-day (CE/d) (Rajkumar et al. 2013). Over 12 months, pulse wave velocity (PWV) and heart rate variability (HRV) changed in a dose-dependent manner such that a one $\mathrm{CE} / \mathrm{d}$ decrease was associated with a $2.3 \%$ higher RMSSD (root mean squared of successive differences in the $R-R$

R. Laumbach $\cdot$ H. Kipen $(\bowtie)$

Environmental and Occupational Health Sciences Institute,

Rutgers-Robert Wood Johnson Medical School, 170

Frelinghuysen Road, Piscataway, NJ 08854, USA

e-mail: kipen@eohsi.rutgers.edu interval), a $5.7 \%$ higher $\mathrm{HF}$ (high frequency) HRV, and a $15.1 \%$ lower PWV. These findings add support for two distinct mechanisms, vascular dysfunction and autonomic dysfunction, to the strong and consistent epidemiologic associations between reductions in SHS and decreased risk for acute adverse cardiovascular events.

What does this study add to the evidence basis for public health actions to regulate smoking as a danger to nonsmokers? Almost 50 years ago, Sir Austin Bradford Hill put forth his now famous guidelines, notably not criteria, to be considered in support of making a determination of causality between an (occupational) exposure and an outcome (Hill 1965). Beyond robust epidemiological associations from multiple studies, arguably the most important benchmark is biological plausibility or mechanistic data, often from animal models, but increasingly recognized to come from experimental or quasi-experimental human studies with biomarkers.

Since Blanc's ground-breaking 1998 investigation, epidemiologic data on adverse cardiovascular events have accumulated to clearly link smoking restrictions in multiple populations to decreased cardiovascular health events (particularly, acute myocardial infarction) in subsequent months (Tan and Glantz 2012). Parallel data on likely mechanistic underpinnings for these epidemiologic observations have been recently reviewed for both SHS and ambient air pollution (Barnoya and Glantz 2005; Brook et al. 2010). In particular, there are substantial data that link smoking to chronic changes in arterial stiffness (Kubozono et al. 2011; Tomiyama et al. 2010) and arterial stiffness to changes in risk for cardiovascular events (Vlachopoulos et al. 2010). Moreover these, as well as other biomarkers of coagulation and endothelial function reflect change over an acute to subacute to subchronic time frame, allowing conduct of panel studies and quasi-experiments such as the 
partial Swiss hospitality smoking ban considered here (Peters et al. 1997; Rich et al. 2012; Tan et al. 2000).

Acute effects of exposure to SHS on HRV, a marker of autonomic tone, have been shown in previous studies using cross-sectional approaches (Pope 2001; Wilson et al. 2010; Zhang et al. 2013), but Rajkumar et al. present results of the first prospective study to examine the effects of reducing SHS exposure on HRV, with addition of a doseresponse in a real-world setting. Alterations in HRV have been linked to changes in particulate matter air pollution in a number of studies, but the results have not always been consistent, perhaps due to differences in methods and host factors (age, sex, comorbidities, etc.) between studies ( $\mathrm{Pi}$ eters et al. 2012). Although lower HRV has been linked to increased cardiovascular mortality in different at-risk patient groups (Bilchick et al. 2002; Tapanainen et al. 2002), the relatively short-term changes in HRV that have been associated with environmental exposures have not been directly linked to health outcomes. More work is needed to understand how SHS, as well as ambient air pollution, affects HRV, and how changes in autonomic function may mediate adverse cardiovascular outcomes.

We have seen how the power of complementary epidemiologic and mechanistic data, from both human biomarker and animal studies, has led to strong conclusions about causal relationships between ambient air pollution and adverse cardiovascular effects, providing evidence for successive reductions in permissible levels for criteria air pollutants in Europe and the USA. In setting health-protective standards for ambient air pollution, we confront the challenges of clearly defining dose-response relationships, including identification of possible thresholds. For SHS, there is no technical barrier and also no economic barrier to banning smoking completely from workplaces, practically eliminating this source of exposure (Schulz et al. 2012). It's time to do just that.

Acknowledgment This work was partially supported by NIEHS Center Grant P30 ES 005022.

\section{References}

Barnoya J, Glantz SA (2005) Cardiovascular effects of secondhand smoke: nearly as large as smoking. Circulation 111(20):26842698

Bilchick KC et al (2002) Prognostic value of heart rate variability in chronic congestive heart failure (Veterans Affairs' Survival Trial of Antiarrhythmic Therapy in Congestive Heart Failure). Am J Cardiol 90(1):24-28

Brook RD et al (2010) Particulate matter air pollution and cardiovascular disease an update to the scientific statement from the
American Heart Association. Circulation 121(21):2331-23378. doi:10.1161/CIR.0b013e3181dbece1

Eisner MD, Smith AK, Blanc PD (1998) Bartenders' respiratory health after establishment of smoke-free bars and taverns. JAMA 280(22):1909-1914

Hill AB (1965) The environment and disease: association or causation? Proc R Soc Med 58:295-300

Kubozono $\mathrm{T}$ et al (2011) Acute and chronic effects of smoking on arterial stiffness. Circ J 75(3):698-702

Peters A, Doring A, Wichmann HE, Koenig W (1997) Increased plasma viscosity during an air pollution episode: a link to mortality? Lancet 349(9065):1582-1587

Pieters N, Plusquin M, Cox B, Kicinski M, Vangronsveld J, Nawrot TS (2012) An epidemiological appraisal of the association between heart rate variability and particulate air pollution: a meta-analysis. Heart 98(15):1127-1135. doi:10.1136/heartjnl2011-301505

Pope CA (2001) Acute exposure to environmental tobacco smoke and heart rate variability. Environ Health Perspect 109(7):711-716

Rajkumar S, Huynh CK, Bauer GF, Hoffmann S, Roosli M (2013) Impact of a smoking ban in hospitality venues on second hand smoke exposure: a comparison of exposure assessment methods. BMC Public Health 13:536. doi:10.1186/1471-2458-13-536

Rajkumar S et al (2014) The effect of workplace smoking bans on heart rate variability and pulse wave velocity of non-smoking hospitality workers. Int J Public Health. doi:10.1007/s00038014-0545-y

Rich DQ et al (2012) Association between changes in air pollution levels during the Beijing Olympics and biomarkers of inflammation and thrombosis in healthy young adults. JAMA 307(19):2068-2078. doi:10.1001/jama.2012.34881157490

Schulz PJ, Hartung U, Fiordelli M (2012) Effect of smoke-free legislation on Ticino gastronomy revenue. Int J Public Health 57:861-866. doi:10.1007/s00038-012-0402-9

Tan CE, Glantz SA (2012) Association between smoke free legislation and hospitalizations for cardiac, cerebrovascular and respiratory diseases: a meta-analysis. Circulation 126(18): 2177-2183. doi:10.1161/CIRCULATIONAHA.112.121301

Tan WC et al (2000) The human bone marrow response to acute air pollution caused by forest fires. Am J Respir Crit Care Med 161:1213-1217

Tapanainen JM et al (2002) Fractal analysis of heart rate variability and mortality after an acute myocardial infarction. Am J Cardiol 90(4):347-352

Tomiyama $\mathrm{H}$ et al (2010) Continuous smoking and progression of arterial stiffening: a prospective study. J Am Coll Cardiol 55(18):1979-1987. doi:10.1016/j.jacc.2009.12.042

Vlachopoulos C, Aznaouridis K, Stefanadis C (2010) Prediction of cardiovascular events and all-cause mortality with arterial stiffness: a systematic review and meta-analysis. J Am Coll Cardiol 55(13):1318-1327. doi:10.1016/j.jacc.2009.10.061

Wilson MD, McGlothlin JD, Rosenthal FS, Black DR, Zimmerman NJ, Bridges CD (2010) Ergonomics: the effect of occupational exposure to environmental tobacco smoke on the heart rate variability of bar and restaurant workers. J Occup Environ Hyg 7(7):D44-D49. doi:10.1080/15459624.2010.483980

Zhang JM, Fang SNC, Mittleman MA, Christiani DC, Cavallari JM (2013) Secondhand tobacco smoke exposure and heart rate variability and inflammation among non-smoking construction workers: a repeated measures study. Environ Health 12(1):83. doi:10.1186/1476-069x-12-83 